\title{
Oral and Intravenous Iodine Treatment - A Hope to Treat 2019-nCoV Virus Infected Patients
}

\author{
Mohammad Azizur Rahman* \\ Professor of Respiratory Medicine, Under Faculty of Medicine, Dhaka University, \\ Dhaka, Bangladesh \\ *Corresponding Author: Mohammad Azizur Rahman, Professor of Respiratory \\ Medicine, Under Faculty of Medicine, Dhaka University, Dhaka, Bangladesh.
}

Received: July 14, 2020

Published: September 11, 2020

(C) All rights are reserved by Mohammad

Azizur Rahman.

\begin{abstract}
To present intravenous iodine infusion (IVI) treatment, which has been used in serious bacterial infections in the past and has been off the agenda with widely used antibiotics. With the antiviral feature of iodine, to report the rationale of the use in patients with coronavirus infected and symptomatic patients. Also, to report the effective use of iodine therapy as an antiviral product that is safe, easy to use, easy to access and extremely cost-effective in the event of a possible excessive patient burden in hospitals.

Keywords: Intravenous Iodine Infusion (IVI); 2019-nCoV Virus
\end{abstract}

\section{Introduction}

Iodine, which is widely used in clinics as a general antiseptic (including antiviral, antibacterial-spores, antifungal, antiparasite), is a very important element in terms of its physiological functions.

\section{Antiviral effectiveness}

Iodine solution (10\% Povidone-iodine) is highly effective in eliminating coronavirus, poliovirus and adenovirus species on inanimate surfaces $[1,2]$. It has been reported that iodine solution is effective virucidal for rhinovirus and coronavirus species in upper respiratory tract by oral washing [3,4]. Irrigation is effective 2 - 4 times a day with $2.5 \%$ Betadine (iodine) solution in the treatment of viral (Adenovirus) conjunctivitis.

Prognostic importance of detecting of the pandemic factor virus in plasma

There are 3 stages in the clinical progression of the 2019-nCoV virus (Figure 1).

Stage 1: Early infection. Dry cough, diarrhea, headache, less than 37.2 fever. Lymphopenia, prothrombin time elevation and LDH elevation. At this stage, viremia is not observed.

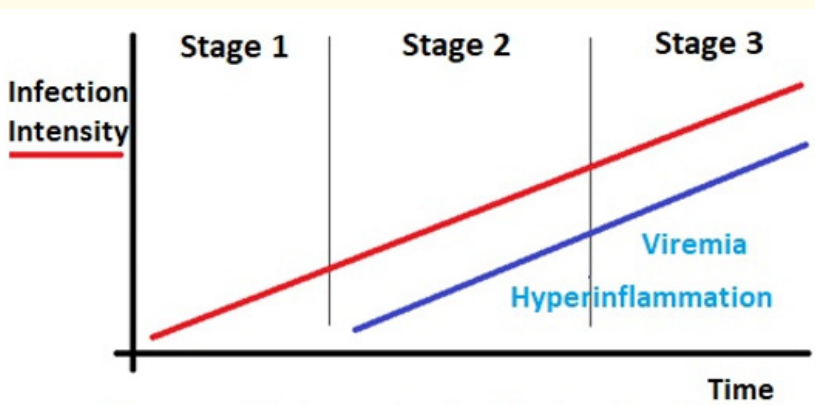

Figure 1: Correlation between intensity of infection and hyperinflammation.

Stage 2: Pulmonary phase. Shortness of breath, Hypoxia $\left(\mathrm{PaO}_{2}\right.$ $/ \mathrm{FiO}_{2}<300 \mathrm{mmHg}$ ). Abnormal appearance and procalcitonin decrease in chest $x$-ray in the following clinic. The virus has begun to enter the blood and the patient's immune system is ready to overreact. The mortality rate is $15 \%$ [5-7].

Stage 3 III: Hyper-inflammatory phase. There is viremia and the immune system overreacts with cytokines, inflammation becomes evident in the lungs and respiratory distress develops. CRP, 
LDH, D-dimer, Ferritin, IL-6, troponin increase. Finally, cardiac failure occurs. The mortality rate is 50\% [5-7].

Detection of 2019-nCoV viral RNA in the blood has been demonstrated in a new study from China, where it is a strong indicator of clinical violence and poor prognosis [8]. Therefore, as the stage progresses, the virus is seen in extrapulmonary regions and turns into a systemic disease.

A systemic antiviral treatment is needed to control the disease in the intermediate and advanced stages. However, since there is no specific antiviral against the virus, IODINE in appropriate doses and can be used in treatment as a general antiviral agent. In the intermediate and advanced stages, since the disease is systemic, antiviral therapy should also be systemic (IV infusion).

\section{IV iodine infusion applications}

Now a days, IV iodine applications are rarely performed by giving contrast material (300 - $1221 \mathrm{mg} / \mathrm{kg}$ iodine) containing iodine for radiodiagnostic purposes (coronary angiography and CT) [9]. In addition, Iodine-131 (10 - $100 \mathrm{mCi}$, about 8 - $80 \mathrm{mg}$ ) is administered via the venous or artery as radioactive iodine therapy [10]. Intravenous iodine treatments were first used in severe bacterial infections in 1920s in IV-infusion, IV-push and intraarterial high doses [11-16]. With the widespread use of antibiotics, IV iodine administration was stopped. Porter reported daily IV infusions in influenza and streptococcal infections, and treatments that repeat these injections 3 or 4 times [13]. In addition, in influenza pneumonia, 30 - $45 \mathrm{mg}$ of iodine (iodine) injection in $9 \mathrm{ml}$ saline daily, repeated these injections once a day for 2 or 3 days, and reported successful results in nine of 10 patients [11].

Mukherjee used intravenously in septic wounds, in cases of Connor septicemia $[12,13]$. Jeudwine has published a large case experience of 400 patients, injecting $32-64 \mathrm{mg}$ of iodine in $10 \mathrm{ml}$ of distilled water or 32 - $64 \mathrm{mg}$ of iodine tincture (1 - $2 \mathrm{ml}$ ) directly into the vein. Due to the very high iodine concentration, he reported pain at the injection site, fever that could last for two hours, and only 2 cases developed severe thrombosis within 1000 injections. He reported that he had effective results in many patients, including patients with pneumonia, septic lung and asthma [14]. Castro injected 30 - $90 \mathrm{mg}$ of iodine IV in $10 \mathrm{ml}$ saline in pneumonia patients [15]. Bharadwaj reported that in approximately 100 plague patients, it achieved cure with $80 \%$ success with intravenous iodine treatment. In his patients, he administered 150 - $300 \mathrm{mg}$ of iodine in 5 - $10 \mathrm{ml}$ of distilled water daily. He reported that the solution prepared with distilled water compared to tincture (alcoholic solution) eliminated the risk of thrombosis and increased the number of leukocytes [16].

Povidone-iodine $10 \%$ was administered as an intravenous infusion to reduce HIV burden in the blood and prevent opportunistic infections $[17,18]$.

\section{Iodine treatment according to the stages}

Stage 1: Controlled Immune Response, Upper Respiratory Tract Infection (Ambulatory/Home Follow-up).

Treatment: $25 \mathrm{mg}$ (4 drops) of Lugol 5\% solution in $200 \mathrm{ml}$ of water and drink after gargling (Health personnel at risk of contamination can also use).

Stage 2: Lower Respiratory Tract Infection, shortness of breath, hypoxia, chest X-ray abnormality. (Bed service).

Treatment: 1 unit of IV infusion per day.

Stage 3: Hyperinflamation (high acute phase reactants), Respiratory Distress (Intensive Care).

Treatment: In the first two days, 1 unit of IV infusion every 12 hours. 1 or 2 units of IV infusion per day, according to the clinical response. When the general condition improves, iodine treatment is ended.

\section{Conclusion}

The antiviral effect of IV-Iodine infusion therapy is predicted in patients with high mortality rate. The application dose is far below past application doses. Follow-up of patients with thyroid hormone panel is recommended. Iodine treatment is a safe treatment that is easy to apply, easy to reach, very low treatment costs and prepared with distilled water. This treatment will allow for easily applicable treatment in inpatient or intensive care units when possible excessive patient admissions.

\section{Bibliography}

1. Sattar SA., et al. "Chemical disinfection of non-porous inanimate surfaces experimentally contaminated with four human pathogenic viruses". Epidemiology and Infection 102.3 (1989): 493-505. 
2. Yoshida. "Relationship between virucidal efficacy and free iodine concentration of povidone iodine in buffer solutions". Biocontrol Science 21.1 (2016): 21-27.

3. Kariwa H., et al. "Inactivation of SARS Coronavirus by means of Povidone-Iodine, Physical Conditions and Chemical Reagents". Dermatology 212.1 (2006): 119-123.

4. https://www.oralhealthgroup.com/features/molecular-iodine-could-this-be-a-game-changer-for-dentistry/

5. Lauer SA., et al. "The incubation period of Coronavirus Disease 2019 (Covid-19) from publicly confirmed cases: Estimation and application". Annals of Internal Medicine 172.9 (2020): 577-582.

6. Ferguson NM., et al. "Impact of non-pharmaceutical intervention (NPIs) to reduce Covid-19 mortality and healthcare demand". Imperial College Covid-19 Response Team (2020).

7. Yang Liu., et al. "Viral Dynamics in mild and severe cases of Covid-19". The Lancet (2020).

8. Chen., et al. "Detectable 2019-nCoV viral RNA in blood is a strong indicator for the further clinical severity". Emerging Microbes and Infections 9.1 (2020): 469-473.

9. Gartner W and Weissel M. "Do iodine-containing contrast media induce clinically relevant changes in thyroid function parameters of euthyroid patients within the first week?" Thyroid 14.7 (2004): 521-524.

10. Kuanrakcharoen P. "Radioiodine (1-131) Dose for the Treatment of Hyperthyroidism in Rajavithi Hospital”. Journal of the Medical Association of Thailand 99.2 (2016): S123-S129.

11. Porter FJW. "A Plea for the More Frequent Use of Intravenous Medication with Special Reference to the Use of Iodine". The Indian Medical Gazette 56.5 (1921): 161-162.

12. Mukherjee PB. "Intravenous Iodine in the Treatment of Septic Wounds". The Indian Medical Gazette 58.11 (1923): 537-538.

13. Connor FP. "The Use of Intravenous Injections of Iodine in the Treatment of Septicæmia and Other Septic Conditions". Medicine Gaz 59.3 (1924): 125-126.

14. Jeudwine WW. "The Therapeutic Value of Intravenous Iodine. Based on Three Years' Experience on 400 Cases". The Indian Medical Gazette 58.12 (1923): 561-571.
15. De Castro. "Intravenous Iodine Injections". The Indian Medical Gazette 60.3 (1925): 141.

16. Bharadwaj AC. "The Treatment of Bubonic Plague with Intravenous Injections of Iodine". The Indian Medical Gazette 61.2 (1926): 63-64.

17. Yolcuoglu Burhan. Robert Cathcart (1992).

18. Werbin N. "Polyvinyl pyrrolidone-iodine as an intravenous antiseptic". Medical Hypotheses 17.2 (1985): 147-148.

\section{Assets from publication with us}

- Prompt Acknowledgement after receiving the article

- Thorough Double blinded peer review

- Rapid Publication

- Issue of Publication Certificate

- High visibility of your Published work

Website: www.actascientific.com/

Submit Article: www.actascientific.com/submission.php Email us: editor@actascientific.com

Contact us: +919182824667 